\begin{tabular}{|l|l|}
$\begin{array}{l}\text { Postprint } \\
\text { Version }\end{array}$ & 1.0 \\
\hline Journal website & http://www.ejcancer.info/article/S0959-8049(13)00112-3/abstract \\
\hline Pubmed link & $\underline{\text { http://www.ncbi.nlm.nih.gov/pubmed/23473614 }}$ \\
\hline DOI & 10.1016/j.ejca.2013.02.004
\end{tabular}

This is a NIVEL certified Post Print, more info at http://www.nivel.eu

\title{
Reply letter to: Do breast cancer survivors visit their General Practitioner for psychological problems? - Reply to Heins et al.: For which health problems do cancer survivors visit their General Practitioner?
}

\author{
MARIANNE J. HeINS ${ }^{A, \Uparrow}$, JOKE C. KOREVAAR ${ }^{A}$, MIEKE RIJKEN ${ }^{A}$, FRANÇOIS G. SCHELlEVIS \\ $\mathrm{A}, \mathrm{B}$

\footnotetext{
${ }^{a}$ Netherlands Institute for Health Services Research (NIVEL), Utrecht, The Netherlands ${ }^{\mathrm{b}}$ Department of General Practice/EMGO, Institute for Health and Care Research, VU University Medical Center, Amsterdam, The Netherlands
}

We would like to thank Roorda et al. ${ }^{1}$ for their letter regarding our article about primary care use of cancer survivors. ${ }^{2}$ They question our conclusion that psychosocial problems are not a major cause for increased primary health care use by breast cancer patients. They hypothesise that when breast cancer patients consult their General Practitioner (GP) for psychosocial issues, the GP may record cancer as the reason for their visit instead of psychosocial problems and this would lead to an underestimation of the role of psychosocial problems. They support their hypothesis with findings from their study, where they found an increase in prescription rates of nervous system drugs in patients with breast cancer. ${ }^{3}$ We performed additional analyses to check if this was the case in our dataset and found increased prescription rates of nervous system drugs (Anatomical Therapeutic Chemical (ATC) anatomical main group $\mathrm{N}$ ) in our study population: $48 \%$ of the breast cancer patients received nervous system drugs versus $38 \%$ of noncancer controls ( $\mathrm{X}^{2}$ test $\mathrm{p}<0.001$ ). Our data confirm the findings of Roorda et al.

However, the main issue that Roorda et al. raised was that we may have underestimated the number of GP contacts due to psychosocial problems, because GPs do not record these problems as the reason for a visit.

To test this hypothesis, we looked at the number of GP contacts where a prescription for nervous system drugs was given without a psychosocial diagnosis. We compared the percentage of GP contacts in which nervous system drugs were prescribed without a psychosocial diagnosis among cancer patients and non-cancer controls and found a percentage of $8 \%$ in cancer patients and $7 \%$ in the control group. There was 
Heins, M.J., Korevaar, J.C., Rijken, M., Schellevis, F.G. Reply letter to: Do breast cancer survivors visit their General Practitioner for psychological problems? - Reply to Heins et al.: For which health problems do cancer survivors visit their General Practitioner? European Jou世nal 7 of Cancer: 2013, 49(7), 1793-1794

no difference between the two groups, and this makes it unlikely that we missed psychosocial problems of cancer patients because they were not recorded as such by the GPs.

We agree with Roorda et al. that breast cancer can have a profound and long-term psychological impact. However, we maintain our conclusion that psychosocial problems do not seem to be a major cause of increased primary care use by breast cancer patients. Only a small fraction of additional visits by breast cancer patients was related to psychosocial problems. Based on the findings described previously, it seems unlikely that we have underestimated this number. As Dutch GPs are or will increasingly play an important role in the after care of cancer patients, ${ }^{4}$ this is an important message for those working in the primary care sector.

\section{CONFLICT OF INTEREST STATEMENT}

None declared.

\section{REFERENCES}

1. Roorda C, De Bock G, Berendsen A. Do breast cancer survivors visit their General Practitioner for psychological problems? Reply to: Heins et al.: For which health problems do cancer survivors visit their General Practitioner? Eur J Cancer 2013.

2. Heins MJ, Korevaar JC, Rijken PM, Schellevis FG. For which health problems do cancer survivors visit their General Practitioner? Eur J Cancer 2013;49(1):211-8.

3. Roorda C, Berendsen AJ, Groenhof F, van der Meer K, de Bock GH. Increased primary healthcare utilisation among women with a history of breast cancer. Support Care Cancer 2012 [Epub ahead of print].

4. Signaleringscommissie KWF Kankerbestrijding. Nazorg bij kanker: rol van de eerste lijn [Aftercare for cancer; the role of primary care]; 2011. 